\title{
Exercise electrocardiography and computed tomography coronary angiography: use of combined functional and anatomical testing in stable angina pectoris
}

\author{
Stella Kyung, Mina M. Benjamin, Mark Rabbat \\ Department of Cardiology, Loyola University Medical Center, Maywood, IL, USA \\ Correspondence to: Mark G. Rabbat, MD, FACC, FAHA, FSCCT. Associate Professor of Medicine and Radiology, Division of Cardiology, Loyola \\ University Medical Center, Chicago, IL, USA. Email: mrabbat@lumc.edu.
}

Provenance and Peer Review: This article was commissioned by the editorial office, Quantitative Imaging in Medicine and Surgery. The article did not undergo external peer review.

Comment on: Singh T, Bing R, Dweck MR, van Beek EJR, Mills NL, Williams MC, Villines TC, Newby DE, Adamson PD. Exercise Electrocardiography and Computed Tomography Coronary Angiography for Patients With Suspected Stable Angina Pectoris: A Post Hoc Analysis of the Randomized SCOT-HEART Trial. JAMA Cardiol 2020;e201567.

Submitted Jul 30, 2020. Accepted for publication Aug 10, 2020.

doi: 10.21037/qims-2020-23

View this article at: http://dx.doi.org/10.21037/qims-2020-23

Coronary artery disease (CAD) is the leading cause of death in the United States in both men and women (1). It is therefore crucial to have optimal diagnostic modalities for diagnosis, prognostication and follow up of CAD patients. Coronary computed tomography angiography (CCTA) is advantageous in its ability to delineate coronary anatomy, including evaluation of the arterial lumen and surrounding atherosclerotic plaque to identify presence and severity of CAD. CCTA also allows evaluation of plaque composition and identifying those with high risk features (2). In addition, the inference of the physiologic, flow-limiting significance of anatomically detected lesions is possible, further aiding clinical decision making for physicians (3-5).

Studies that have investigated the usefulness of CCTA in evaluation of acute chest pain found that patients seen in the emergency department for symptoms suggestive of acute coronary syndrome had reduced length of stay and were admitted less frequently when evaluated with CCTA, in comparison to standard care (6). The PROMISE trial showed that CCTA is an alternative to standard care in evaluation of patients in an outpatient setting with chest pain. When compared with functional testing such as exercise electrocardiography (ECG), nuclear stress testing, or stress echocardiography, anatomical testing with CCTA was found to have similar clinical outcomes (7). The CRESCENT trial also showed that CCTA is a cost-effective and safe alternative to functional testing, which included exercise ECG, nuclear stress testing, and stress echocardiography (8). In fact, a contemporary systematic review and meta-analysis of over 20,000 patients determined that, compared with functionalstress testing, CCTA was associated with reduced incidence of myocardial infarction (9).

The SCOT-HEART trial studied the added value of CCTA compared to standard care, which composed primarily of exercise stress ECG testing, in patients with stable angina pectoris (10). Patients with CCTA were found to have lower rates of composite end point of death from CAD or nonfatal myocardial infarction (MI) at 5 years $(2.3 \%$ vs. $3.9 \%)$. The composite end point was primarily driven by nonfatal MI; this may be due to the additional information from CCTA leading to better targeting of patients for preventative care. Patients with evidence of any CAD on CCTA, whether obstructive or nonobstructive, were prescribed preventative therapies. This is in comparison to the standard therapy, where patients with an ASSIGN score (11) of $\geq 20$ were prompted to be prescribed 
preventative therapies. The use of CCTA to target preventative therapy may have detected patients with nonobstructive lesions that would be otherwise missed by standard evaluations. Additionally, it is important to note that patients with CCTA did not have increased use of coronary angiography or revascularization at 5 years.

A post-hoc analysis of the SCOT-HEART trial evaluated the incremental value of CCTA over stress ECG alone (12). Of the 4,146 patients recruited for the SCOT-HEART trial, 3,283 (79\%) patients were referred for exercise ECG prior to randomization. In the total studied population, results of most exercise ECGs were normal (67\%), leaving the minority of the studies with abnormal (16\%) or inconclusive $(17 \%)$ results. Of these patients, half were randomized to undergo CCTA in addition to standard care and the other half underwent standard care alone. CAD was identified as normal if stenosis $<10 \%$, nonobstructive if stenosis $\geq 10 \%$ and $\leq 70 \%$, and obstructive if stenosis $>70 \%$ on CCTA and on invasive coronary angiogram. Abnormal exercise stress ECG test results were associated with a 14.47 -fold $(\mathrm{P}<0.001)$ increase in coronary revascularization at 1 year and a 2.57 fold $(\mathrm{P}<0.001)$ increase in mortality from coronary heart disease or in nonfatal MI at 5 years. The combination of exercise stress ECG with CCTA, which provides added anatomical testing, showed a stronger association with future risk of adverse cardiac events when compared with exercise stress testing alone (hazard ratio 10.63, $\mathrm{P}=0.002$ ). The authors concluded that the additive value of functional and anatomical testing can be used to better detect and treat CAD

The stress ECG results of the post-hoc analysis are congruent with previously published studies in regards to the importance of and pitfalls of the functional testing modality (13). Exercise ECG had a sensitivity of 39\% and a specificity of $91 \%$ for detecting obstructive CAD in those who underwent subsequent invasive coronary angiography. Interestingly, the participants with abnormal exercise ECG were more likely to be on antiplatelet therapy $(\mathrm{P}<0.001)$ and statin therapy $(\mathrm{P}<0.001)$, regardless of the study allocation. Conversely, those with a normal or inconclusive exercise ECG result were more likely to be initiated on antiplatelet $(\mathrm{P}<0.001)$ and statin $(\mathrm{P}<0.001)$ therapies; these patients were more likely to undergo changes to their preventive therapy and undergo referral for invasive coronary angiography if they underwent CCTA. This may be because, of those who underwent CCTA, more than half of the patients with normal exercise ECG results were found to have CAD (15\% obstructive and $41 \%$ nonobstructive). On the other hand, of the patients with obstructive CAD on CCTA, 137 (39\%) of the patients had a normal exercise ECG.

In review of the data, it is notable that essential details of the exercise ECG such as exercise time, ST segment changes, hemodynamic response, and chronotropic response were not included in the analysis (12). Rather, the exercise ECG results that were identified as normal, abnormal, or inconclusive by the attending physician were recorded without independent adjudication. This may be significant, as exercise time might affect the size of the ischemic area on myocardial perfusion imaging and influenced the results of the study (14). Additionally, the lack of stress ECG details and reassessment of stress ECG results adds a possible element of inter-reader variability that may have affected the overall results.

Although CCTA detection of CAD was helpful in increasing preventative therapy, the overall medical management differences between those who underwent CCTA and standard therapy were modest and are unlikely to explain the difference in nonfatal MI alone. Indeed, more appropriate and increased upfront referral to invasive coronary angiography and subsequent percutaneous coronary intervention contributed to the improved outcome.

Still, the additive value of CCTA in addition to exercise ECG is undeniable: CCTA findings were strongly associated with risk of myocardial infarction, particularly for those with normal or inconclusive results of exercise ECG. This is important to note, as the 2012 American Heart Association guidelines (15) and the 2019 European Society of Cardiology guidelines (13) support the use of CCTA if noninvasive testing is contraindicated or if exercise ECG results are inconclusive, as CCTA increases the certainty of diagnosis of CAD in patients with chest pain. In addition, the National Institute for Health and Care Excellence (NICE) stable chest pain guidelines recommend CCTA in lieu of functional testing as the first-line test for the evaluation of patients with chest pain (14).

CCTA is able to detect unrecognized CAD and therefore allows for better targeting of preventative therapies and interventions. Another subanalysis of the SCOT-HEART by Williams et al. (16) evaluated the association between lowattenuation plaque burden with the future risk of fatal or nonfatal MI. The study showed that low attenuation plaque burden was the strongest predictor for MI (adjusted hazard ratio 1.60 per doubling, $\mathrm{P}=0.014$ ) compared with, and irrespective of, cardiovascular risk score, coronary artery 
calcium score, and coronary artery area stenosis (16). The authors concluded that these findings challenge the current classical risk factors for MI, including stenosis severity, and provide incremental prediction of $\mathrm{MI}$ in addition to standard assessments. Incorporating the evaluation for lowattenuation plaque can be readily accomplished, as plaque can be semi-automatically measured on imaging of standard CCTAs.

Coronary plaque evaluation using CCTA can be done serially to assess CAD progression and response to therapy. Statin therapy has been associated with increased progression of calcified coronary plaque and significantly reduced progression of noncalcified plaque; this may reflect calcification of the noncalcified plaque component as healing and plaque stabilization through calcification of the necrotic core $(17,18)$. In addition, the interim results of EVAPORATE trial demonstrated slower progression of total non-calcified plaque, total plaque, fibrous plaque and calcified plaque with icosapent ethyl compared to placebo in statin-treated patients measured by serial CCTA (19).

Functional and anatomical testing can be used to better detect and treat CAD. Singh et al showed that the combination of CCTA and exercise ECG results had a stronger association with future risk of adverse cardiac events than when compared with exercise stress testing alone (12). Therefore, a combination of anatomical and functional testing is beneficial for patient risk factor modification and therapy. CCTA has the additive benefit of functional evaluation of coronary artery stenosis with fractional flow reserve derived from CCTA datasets $\left(\mathrm{FFR}_{\mathrm{CT}}\right)$ $(20,21)$. For example, in patients with multivessel CAD, CCTA with $\mathrm{FFR}_{\mathrm{CT}}$ was non-inferior to invasive coronary evaluation in decision making and in identifying targets for revascularization (22). Recently, Rabbat et al. reported the safe deferral of invasive coronary angiography in patients with stable CAD using a diagnostic strategy of $\mathrm{FFR}_{\mathrm{CT}}$ (23). Ongoing prospective, pragmatic, randomized clinic trials such as PRECISE (Prospective Randomized Trial of the Optimal Evaluation of Cardiac Symptoms and Revascularization) will shed light on the optimal diagnostic strategy for patients with suspected CAD.

There has been extensive research highlighting the utility and use of CCTA in the diagnosis and management of CAD since the 2012 AHA guidelines were published. CCTA offers a safe and non-inferior to superior alternative to other modalities for CAD evaluation, with the additive value of being able to provide both anatomical and functional testing with novel applications such as $\mathrm{FFR}_{\mathrm{CT}}$.

\section{Acknowledgments}

Funding: None.

\section{Footnote}

Conflicts of Interest: All authors have completed the ICMJE uniform disclosure form (available at http://dx.doi. org/10.21037/qims-2020-23). MR reports other from HeartFlow, outside the submitted work. The other authors have no conflicts of interest to declare.

Open Access Statement: This is an Open Access article distributed in accordance with the Creative Commons Attribution-NonCommercial-NoDerivs 4.0 International License (CC BY-NC-ND 4.0), which permits the noncommercial replication and distribution of the article with the strict proviso that no changes or edits are made and the original work is properly cited (including links to both the formal publication through the relevant DOI and the license). See: https://creativecommons.org/licenses/by-nc-nd/4.0/.

\section{References}

1. Nowbar AN, Gitto M, Howard JP, Francis DP, AlLamee R. Mortality From Ischemic Heart Disease. Circ Cardiovasc Qual Outcomes 2019;12:e005375.

2. Miller JM, Rochitte CE, Dewey M, Arbab-Zadeh A, Niinuma H, Gottlieb I, Paul N, Clouse ME, Shapiro EP, Hoe J, Lardo AC, Bush DE, de Roos A, Cox C, Brinker J, Lima JA. Diagnostic performance of coronary angiography by 64-row CT. N Engl J Med 2008;359:2324-36.

3. Nørgaard BL, Leipsic J, Gaur S, Seneviratne S, Ko BS, Ito H, Jensen JM, Mauri L, De Bruyne B, Bezerra H, Osawa K, Marwan M, Naber C, Erglis A, Park SJ, Christiansen EH, Kaltoft A, Lassen JF, Botker HE, Achenbach S, Group NXTTS. Diagnostic performance of noninvasive fractional flow reserve derived from coronary computed tomography angiography in suspected coronary artery disease: the NXT trial (Analysis of Coronary Blood Flow Using CT Angiography: Next Steps). J Am Coll Cardiol 2014;63:1145-55.

4. Celeng C, Leiner T, Maurovich-Horvat P, Merkely B, de Jong P, Dankbaar JW, van Es HW, Ghoshhajra BB, Hoffmann U, Takx RAP. Anatomical and Functional Computed Tomography for Diagnosing Hemodynamically Significant Coronary Artery Disease: A Meta-Analysis. JACC Cardiovasc Imaging 2019;12:1316-25. 
5. Driessen RS, Danad I, Stuijfzand WJ, Raijmakers PG, Schumacher SP, van Diemen PA, Leipsic JA, Knuuti J, Underwood SR, van de Ven PM, van Rossum AC, Taylor CA, Knaapen P. Comparison of Coronary Computed Tomography Angiography, Fractional Flow Reserve, and Perfusion Imaging for Ischemia Diagnosis. J Am Coll Cardiol 2019;73:161-73.

6. Hoffmann U, Truong QA, Schoenfeld DA, Chou ET, Woodard PK, Nagurney JT, Pope JH, Hauser TH, White CS, Weiner SG, Kalanjian S, Mullins ME, Mikati I, Peacock WF, Zakroysky P, Hayden D, Goehler A, Lee H, Gazelle GS, Wiviott SD, Fleg JL, Udelson JE, Investigators R-I. Coronary CT angiography versus standard evaluation in acute chest pain. N Engl J Med 2012;367:299-308.

7. Douglas PS, Hoffmann U, Patel MR, Mark DB, AlKhalidi HR, Cavanaugh B, Cole J, Dolor RJ, Fordyce CB, Huang M, Khan MA, Kosinski AS, Krucoff MW, Malhotra V, Picard MH, Udelson JE, Velazquez EJ, Yow E, Cooper LS, Lee KL, Investigators P. Outcomes of anatomical versus functional testing for coronary artery disease. $\mathrm{N}$ Engl J Med 2015;372:1291-300.

8. Lubbers M, Dedic A, Coenen A, Galema T, Akkerhuis J, Bruning T, Krenning B, Musters P, Ouhlous M, Liem A, Niezen A, Hunink M, de Feijter P, Nieman K. Calcium imaging and selective computed tomography angiography in comparison to functional testing for suspected coronary artery disease: the multicentre, randomized CRESCENT trial. Eur Heart J 2016;37:1232-43.

9. Foy AJ, Dhruva SS, Peterson B, Mandrola JM, Morgan DJ, Redberg RF. Coronary Computed Tomography Angiography vs Functional Stress Testing for Patients With Suspected Coronary Artery Disease: A Systematic Review and Meta-analysis. JAMA Intern Med 2017;177:1623-31.

10. SCOT-HEART Investigators, Newby DE, Adamson PD, Berry C, Boon NA, Dweck MR, Flather M, Forbes J, Hunter A, Lewis S, MacLean S, Mills NL, Norrie J, Roditi G, Shah ASV, Timmis AD, van Beek EJR, Williams MC. Coronary CT Angiography and 5-Year Risk of Myocardial Infarction. N Engl J Med 2018;379:924-33.

11. Woodward M, Brindle P, Tunstall-Pedoe H, estimation Sgor. Adding social deprivation and family history to cardiovascular risk assessment: the ASSIGN score from the Scottish Heart Health Extended Cohort (SHHEC). Heart 2007;93:172-6.

12. Singh T, Bing R, Dweck MR, van Beek EJR, Mills NL, Williams MC, Villines TC, Newby DE, Adamson PD. Exercise Electrocardiography and Computed Tomography
Coronary Angiography for Patients With Suspected Stable Angina Pectoris: A Post Hoc Analysis of the Randomized SCOT-HEART Trial. JAMA Cardiol 2020;e201567. doi: 10.1001/jamacardio.2020.1567.

13. Saraste A, Knuuti J. ESC 2019 guidelines for the diagnosis and management of chronic coronary syndromes: Recommendations for cardiovascular imaging. ESCLeitlinien 2019 für die Diagnose und Therapie von chronischen Koronarsyndromen: Empfehlungen für die kardiovaskuläre Bildgebung. Herz 2020;45:409-20.

14. Timmis A, Roobottom CA. National Institute for Health and Care Excellence updates the stable chest pain guideline with radical changes to the diagnostic paradigm. Heart 2017;103:982-6.

15. Fihn SD, Gardin JM, Abrams J, Berra K, Blankenship JC, Dallas AP, Douglas PS, Foody JM, Gerber TC, Hinderliter AL, King SB 3rd, Kligfield PD, Krumholz HM, Kwong RY, Lim MJ, Linderbaum JA, Mack MJ, Munger MA, Prager RL, Sabik JF, Shaw LJ, Sikkema JD, Smith CR Jr, Smith SC Jr, Spertus JA, Williams SV, Anderson JL; American College of Cardiology Foundation/American Heart Association Task Force. 2012 ACCF/AHA/ACP/AATS/PCNA/ SCAI/STS guideline for the diagnosis and management of patients with stable ischemic heart disease: a report of the American College of Cardiology Foundation/American Heart Association task force on practice guidelines, and the American College of Physicians, American Association for Thoracic Surgery, Preventive Cardiovascular Nurses Association, Society for Cardiovascular Angiography and Interventions, and Society of Thoracic Surgeons. Circulation 2012;126:e354-471.

16. Williams MC, Kwiecinski J, Doris M, McElhinney P, D'Souza MS, Cadet S, Adamson PD, Moss AJ, Alam S, Hunter A, Shah ASV, Mills NL, Pawade T, Wang C, Weir McCall J, Bonnici-Mallia M, Murrills C, Roditi G, van Beek EJR, Shaw LJ, Nicol ED, Berman DS, Slomka PJ, Newby DE, Dweck MR, Dey D. LowAttenuation Noncalcified Plaque on Coronary Computed Tomography Angiography Predicts Myocardial Infarction: Results From the Multicenter SCOT-HEART Trial (Scottish Computed Tomography of the HEART). Circulation 2020;141:1452-62.

17. Smit JM, van Rosendael AR, El Mahdiui M, Neglia D, Knuuti J, Saraste A, Buechel RR, Teresinska A, Pizzi MN, Roque A, Poddighe R, Mertens BJ, Caselli C, Rocchiccioli S, Parodi O, Pelosi G, Scholte AJ. Impact of Clinical Characteristics and Statins on Coronary Plaque Progression by Serial Computed Tomography 
Angiography. Circ Cardiovasc Imaging 2020;13:e009750.

18. Li Z, Hou Z, Yin W, Liu K, Gao Y, Xu H, Yu F, Ma Z, Yu W, Yang L, Lu B. Effects of statin therapy on progression of mild noncalcified coronary plaque assessed by serial coronary computed tomography angiography: A multicenter prospective study. Am Heart J 2016;180:29-38.

19. Budoff MJ, Muhlestein JB, Bhatt DL, Le Pa VT, May HT, Shaikh K, Shekar C, Kinninger A, Lakshmanan S, Roy S, Tayek J, Nelson JR. Effect of Icosapent Ethyl on Progression of Coronary Atherosclerosis in Patients with Elevated Triglycerides on Statin Therapy: A prospective, placebo-controlled randomized trial (EVAPORATE): Interim Results. Cardiovasc Res 2020. doi: 10.1093/cvr/ cvaa184.

20. Rabbat MG, Berman DS, Kern M, Raff G, Chinnaiyan K, Koweek L, Shaw LJ, Blanke P, Scherer M, Jensen JM, Lesser J, Norgaard BL, Pontone G, De Bruyne B, Bax JJ, Leipsic J. Interpreting results of coronary computed tomography angiography-derived fractional flow reserve in clinical practice. J Cardiovasc Comput Tomogr 2017;11:383-8.

Cite this article as: Kyung S, Benjamin MM, Rabbat $M$. Exercise electrocardiography and computed tomography coronary angiography: use of combined functional and anatomical testing in stable angina pectoris. Quant Imaging Med Surg 2020;10(11):2218-2222. doi: 10.21037/qims-2020-23
21. Ball C, Pontone G, Rabbat M. Fractional Flow Reserve Derived from Coronary Computed Tomography Angiography Datasets: The Next Frontier in Noninvasive Assessment of Coronary Artery Disease. Biomed Res Int 2018;2018:2680430.

22. Collet C, Onuma Y, Andreini D, Sonck J, Pompilio G, Mushtaq S, La Meir M, Miyazaki Y, de Mey J, Gaemperli O, Ouda A, Maureira JP, Mandry D, Camenzind E, Macron L, Doenst T, Teichgraber U, Sigusch H, Asano T, Katagiri Y, Morel MA, Lindeboom W, Pontone G, Luscher TF, Bartorelli AL, Serruys PW. Coronary computed tomography angiography for heart team decision-making in multivessel coronary artery disease. Eur Heart J 2018;39:3689-98.

23. Rabbat M, Leipsic J, Bax J, Kauh B, Verma R, Doukas D, Allen S, Pontone G, Wilber D, Mathew V, Rogers C, Lopez J. Fractional Flow Reserve Derived from Coronary Computed Tomography Angiography Safely Defers Invasive Coronary Angiography in Patients with Stable Coronary Artery Disease. J Clin Med 2020;9:604. 